\title{
La biblioteca de Éfeso
}

\author{
Javier Rodríguez CABezas *
}

\begin{abstract}
RESUMEN ABSTRACT
Restaurada recientemente, la biblioteca de Éfeso fue erigida por el Recovered recently, the Epheso's library was erected by the consul cónsul Gayo Julio Aquila en honor de su padre, Tiberio Julio Celso Tiberius lulius Aquila in honor of its father, Tiberius lulius Celsus Polemeano, en la segunda década del Polemeanus, in the second decade of siglo $/ 1$ d.C. Como en las grandes bibliotecas de la Antigüedad, conocemos con casi total seguridad su diseño primitivo, pero es seguro que la mayoria de las obras que poblaron sus estantes han desaparecido a lo largo de los tiempos. the II century a.C. Like in the great libraries of the Antiquity, we know with almost tofal security its primitive design, but it's safe that most of the works that populated their shelves they have disappeared throughout the times.
\end{abstract}

\section{INTRODUCCIÓN}

En 1863 un arqueólogo británico, llamado John Turtle Wood, que se encontraba trabajando en la construcción de una red ferroviaria en Turquía, abandonó su trabajo para dedicarse, con tesón y entusiasmo, a realizar excavaciones en la abandonada ciudad de Éfeso ", en busca del Templo de Artemisa, una de las Siete Maravillas del Mundo Antiguo. Las

* Departamento de Prehistoria e Historia Antigua UNED.

John T. Wood, Discoveries at Ephesos, 1877. 
prospecciones se alargaron durante seis años, a lo largo de los cuales Wood dudó si sería posible encontrarlo algún día, hasta que, una mañana del mes de mayo de 1869, encontró la pared del pery/bolos (muro que cerraba el recinto sagrado) del Templo. Poco tiempo después, el doctor Schliemann, que había visitado a Wood unos meses antes, encontraba la mítica ciudad de Troya.

Quizás sea éste el motivo que explique que el hallazgo de Wood no tenga mayor celebridad: cuando se empezaba a difundir la noticia de la aparición del Templo de Artemisa, el mundo de la arqueología se conmocionó con el descubrimiento de la ciudad de Troya. Sin embargo, en otro sentido, la labor de Wood ha llegado hasta hoy en día: abrió el camino a las excavaciones en Éfeso, una ciudad que había permanecido cerca de quinientos años desierta. La ciudad fue fundada por los griegos entre los siglos $x$ y ix a.C., alcanzando su apogeo entre los siglos il a.C. y ill d.C., periodo en el cual fue la ciudad más populosa de Asia Menor y una de las más importantes del Imperio Romano?. La decadencia del Imperio Romano, las primeras invasiones de los pueblos situados más allá del limes oriental, la desintegración del viejo orden social y la aparición del cristianismo contribuyeron al declive de Éfeso, como se verá más tarde, pero otro factor no menos importante precipitó su final.

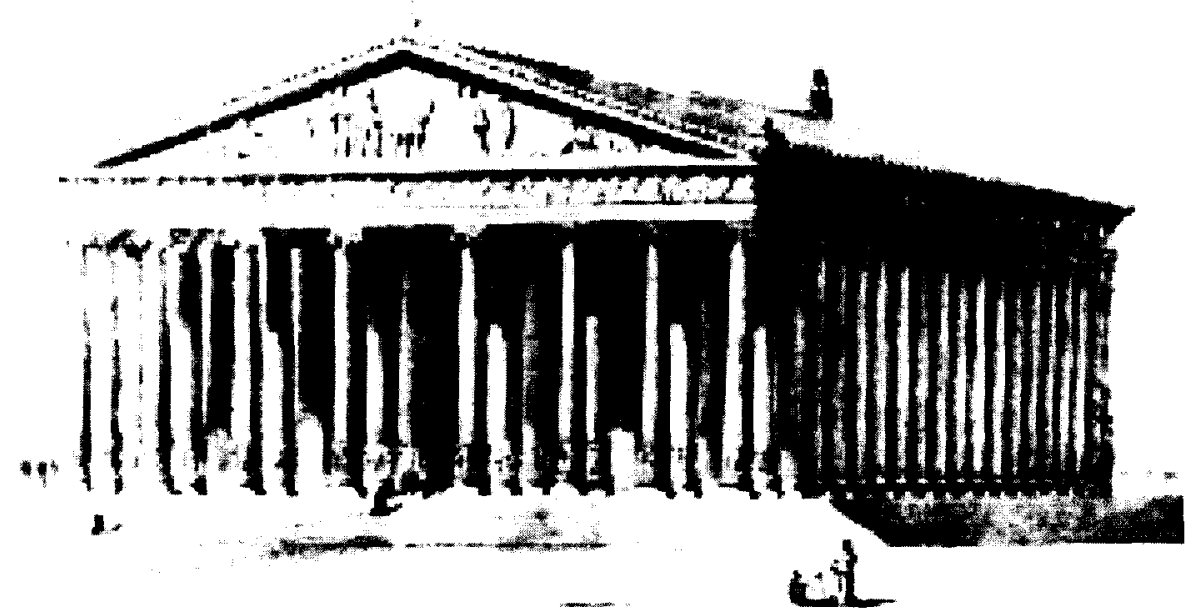

Fig. 1. El templo de Artemisa en Éfeso, una de las Siete Maravillas del Mundo Antiguo.

Las estimaciones rondan los 250.000 habitantes en el apogeo de la ciudad. 
La riqueza de Éfeso desde la época helenística se asentaba básicamente en dos pilares: por una parte, en los ingresos que obtenía del comercio y del turismo como ciudad sede de una de las Siete Maravillas del Mundo Antiguo, el templo de Artemisa, célebre desde siglos atrás entre los griegos, que convirtieron el templo en un importante centro de peregrinación. Esta condición se mantuvo en el mundo romano, en el que era conocido como el templo de Diana. Por otra, este papel de ciudad santuario se reforzaba por su posición de centro económico más importante de Asia. Como encrucijada de las rutas comerciales entre las ciudades del interior y las rutas del Mediterráneo, contaba con el puerto más importante del Egeo ${ }^{3}$. Su situación geográfica contribuyó, no obstante, a acelerar el declive de la ciudad, ya que, situada ésta en la desembocadura del río Caistro, corría el peligro de ver convertido su puerto en una laguna cenagosa e impracticable para la navegación, debido a la gran cantidad de materiales que arrastraba el río a lo largo de su curso y que depositaba luego mansamente en el puerto de la ciudad. En las épocas helenística y romana, el problema de la acumulación de materiales se solventó con el dragado de las aguas del puerto, como sucedió durante la visita que hizo a la ciudad en el año 129 d.C. el emperador Adriano, que puso en marcha un ambicioso proyecto para limpiar de barro el puerto de la ciudad. Sin embargo, en épocas posteriores, en plena decadencia romana, estos trabajos se abandonaron y los aluviones terminaron por impedir la navegación y el amarre de los barcos entre los siglos i $v$ y $\vee$ de nuestra era. Este factor contribuyó decisivamente a la decadencia de Éfeso, que hacia el siglo VII había perdido toda importancia estratégica y económica. Fue tal la intensidad con que se produjeron las deposiciones de materiales que arrastraba el río hasta la ciudad que, según parece, en el siglo $x$ el templo de Artemisa estaba completamente enterrado bajo el limo, hasta el punto de que sobre él se construyeron casas, pozos e incluso un cementerio. Hoy en día, el antiguo puerto es una llanura que se encuentra a más de cinco kilómetros de la costa ${ }^{4}$.

La labor de Wood fue seguida en los años siguientes por un equipo británico dirigido por Hogarth, uno de los arqueólogos más prestigiosos del momento. El equipo completó los trabajos de Wood en los alrededores del Templo de Artemisa, con el hallazgo de un gran número de ofrendas

\footnotetext{
Maurice Chartre, L'Asie Mineure et l'Anatolie d'Alexandre à Dioclétien. Ed. Armand Colin, Paris 1995.

4 Este fenómeno ya fue advertido por WooD, que escribio que "en el curso de las exploraciones que realicé fuera de la ciudad, descubri que toda la llanura de Éfeso habia subido más de tres metros al irse cubriendo de arena y cieno durante los últimos quince siglos..."
} 


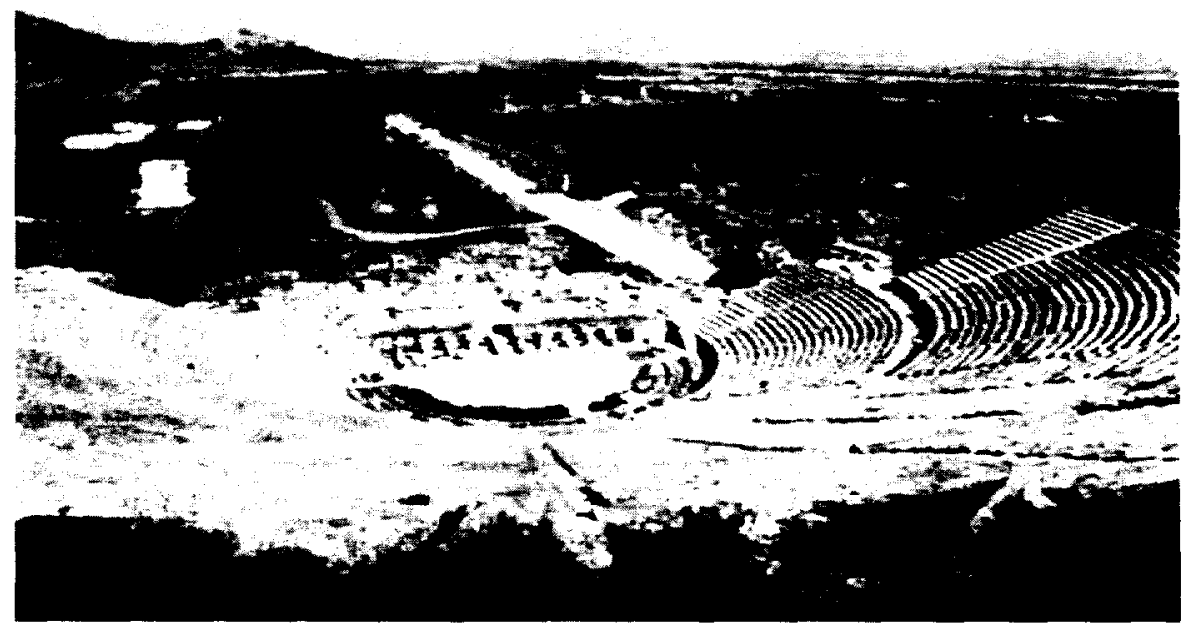

Fig. 2. Vista desde el teatro de la Vía Arcadiana; en su extremo más alejado se encontraba antiguamente el puerto de la ciudad.

votivas, monedas, joyas y otros objetos ${ }^{5}$. Sin embargo, el peso principal de las excavaciones en la antigua ciudad lo llevó el equipo austriaco que comenzó sus excavaciones en el año de 1895, dirigidos por Bendorf, y continuados por el Austrian Archaeological Institute a lo largo de este siglo ${ }^{6}$.

Aparte del magnífico Teatro grecorromano, la ciudad de Éfeso contaba con un gran número de construcciones monumentales, muchas de las cuales fueron restauradas durante este siglo. La mayor parte de ellas se edificaron en nuestra era, coincidiendo con el renacer económico observado en tiempos de Augusto ${ }^{7}$. A partir de su reinado encontramos abundantes inscripciones de construcciones o reconstrucciones, y sobre todo a partir de los Flavios, alcanzando su apogeo constructivo entre los reinados de Trajano y Antonino Pío. Es en esta época cuando los edificios se multiplican y alcanzan un lujo inaudito: enumerar las construcciones de la época

D.G. Hogarth, Excavations at Ephesos, 1906.

- Nuevas excavaciones fueron dirigidas por Keil, Miltner, Eichler y Wetter. En 1995 se cumplió el centenario de la investigación austriaca en Éfeso, celebrándose un simposio internacional, cuyos resultados pueden encontrarse en: FRIESINGER, H.; KRINZINGER, F: 100 Jahre Österreichische Forschungen in Ephesos: Akten des Symposions Wien 1995. Viena, Österreichischen Akademie der Wissenschaften, 1999.

Tanto Estrabón como Plinio constatan este renacer económico, alabando la riqueza y actividad de las ciudades de Asia Menor. 
en Éfeso requeriría de por sí un voluminoso estudio, por lo que únicamente destacaré que la biblioteca de Éfeso, construida en los reinados de Trajano y Adriano, es un testimonio de esta riqueza; la biblioteca de Celso no solo es signo de la bonanza económica, sino que además demuestra que las construcciones no eran exclusivamente imperiales, sino que existía una pujante clase dirigente enriquecida por el comercio ${ }^{8}$.

Sin embargo, con ser evidente la prosperidad que disfrutaba el Asia Menor en el siglo II d.C., no es también menos cierto que desde finales del siglo । d.C., con el nacimiento del cristianismo y el auge de las religiones mistéricas o iniciáticas, se produjo el inicio de una serie de convulsiones religiosas que afectaron profundamente a la sociedad de la época. Una de las fuentes más importantes para conocer la sociedad de la época en Éfeso y en todo el Mediterráneo oriental es la Biblia, principalmente las descripciones contenidas en los Hechos de los Apóstoles, donde se describen los encuentros de Pablo con los efesios y la fuerte oposición que despertaron sus predicaciones entre los comerciantes de la ciudad, cuyo fiel reflejo es el motín de Éfeso ${ }^{9}$.

El cristianismo enraizó fuertemente en una sociedad caracterizada por la división estamental ${ }^{10}$, y con el tiempo supuso un factor de gran trascendencia en la decadencia de Éfeso. Este argumento es evidente si se tiene en cuenta que, a las persecuciones que sufrieron los cristianos en esta época, le siguió la persecución que sufrieron los profanos que adoraban a Artemisa, ya en época cristiana ${ }^{11}$. Más graves fueron, entre los reinados de Valeriano y Galieno (253-268), las incursiones que efectuaron los godos por la costa septentrional del Asia Menor, llegando hasta Éfeso; en el 253 se produjo la primera incursión, que desencadenó el pánico en aquellos territorios; más tarde, en el 262, en una nueva incursión, los godos que llegaron a Éfeso incendiaron el templo de Artemisa, episodio que describió magistralmente Edward Gibbon a finales del siglo XVIII: "Sucesivos imperios, el persa, el macedonio y el romano, veneraron su santidad y enriquecieron su esplendor. Pero los rudos salvajes del Báltico carecian del gusto por las artes elegantes, y despreciaron los terrores

8 Maurice Chartre: El Oriente Romano. Provincias y sociedades provinciales del Madrid 1994. FERGUS MILAR, El Imperio Romano y sus pueblos limitrofes, Historia Universal siglo XX1, Madrid 1990.

Hechos, 19-11/40.

Pablo, Lucas y Juan. Ed. El Almendro, Madrid 1993.

11 El hecho de que fue asi parece probado porque muchas de las inscripciones dedicadas a matio memoriae, es decir, fueron dañadas o destruidas. 
intelectuales de una superstición extranjera" ${ }^{12}$. Es posible, no obstante, que los mayores daños fueran provocados por los cristianos intencionadamente: algunas crónicas cristianas nos han legado la noticia de que la estatua de la diosa que siempre se había alzado en el centro de la ciudad fue quitada, siendo sustituida por una cruz. En cuanto al templo, parece ser que sufrió los mayores daños durante el siglo V, por obra de San Juan Crisóstomo, Patriarca de Constantinopla, quién lo habría despojado de sus riquezas, esculturas $y$, en definitiva, de todo cuanto tenía de valioso ${ }^{13}$.

\section{LA BIBLIOTECA DE ÉFESO}

La biblioteca de Éfeso tampoco sobrevivió a los avatares históricos. De hecho, la reconstrucción efectuada en la década de los 70 es la que nos permite conocer, con bastante seguridad, el aspecto que tendría el edificio en el siglo $\|$ d.C.

La biblioteca, construida aproximadamente entre los años 114 y 120 d.C., fue erigida, como rezan dos inscripciones, por Gayo Julio Aquila Polemeano, consul en el año 110 d.C., en honor a su padre, el insigne Tiberio Julio Celso Polemeano, proconsul de Asia entre los años 106 y 107 d.C. La construcción fue sufragada por Julio Aquila mediante una donación de 25.000 denarios, una cifra magnífica, pero que se podía permitir dada su inmensa fortuna, y fue posteriormente continuada por su hijo, el nieto de Celso.

No cabe duda de que la belleza del edificio asombró a los efesios y a los visitantes de la ciudad. Fue construida encerrada entre otros edificios, de modo que solo la fachada era importante al exterior, y se accedía a ella por una pequeña plaza cubierta de losas de mármol, a la que se llegaba a través de la Avenida de los Curetos, una de las vías principales de la ciudad, o desde el Agora,cruzando la Puerta de Mazaeus y Mitrídates. Desde la pequeña plaza, la biblioteca se mostraba con todo su esplendor: nueve escalones de mármol, flanqueados por dos estatuas, daban paso a una monumental fachada, decorada rica y fantásticamente, en un estilo que recuerda poderosamente los scaenae frons ${ }^{14}$, con cuatro pares de columnas

EDWARD GiBBON, Historia de la decadencia y ruina del Imperio Romano. Madrid, reimp., 1984. Un libro interesante respecto a la historia del templo de Artemisa, lleno de noticias curiosas, es el de Romer, J. y Romer, E.: The Seven Wonders of the World. J\&E Romer Publications, 1996.

${ }_{14}$ Los escenarios de los teatros romanos, como el de Aspendos, y otros edificios, como la Puerta del Mercado de Mileto, son buenos ejemplos de esta arquitectura de líneas barrocas, caracteristicas del arte romano de la época, en el que se mantiene el gusto por las columnatas 


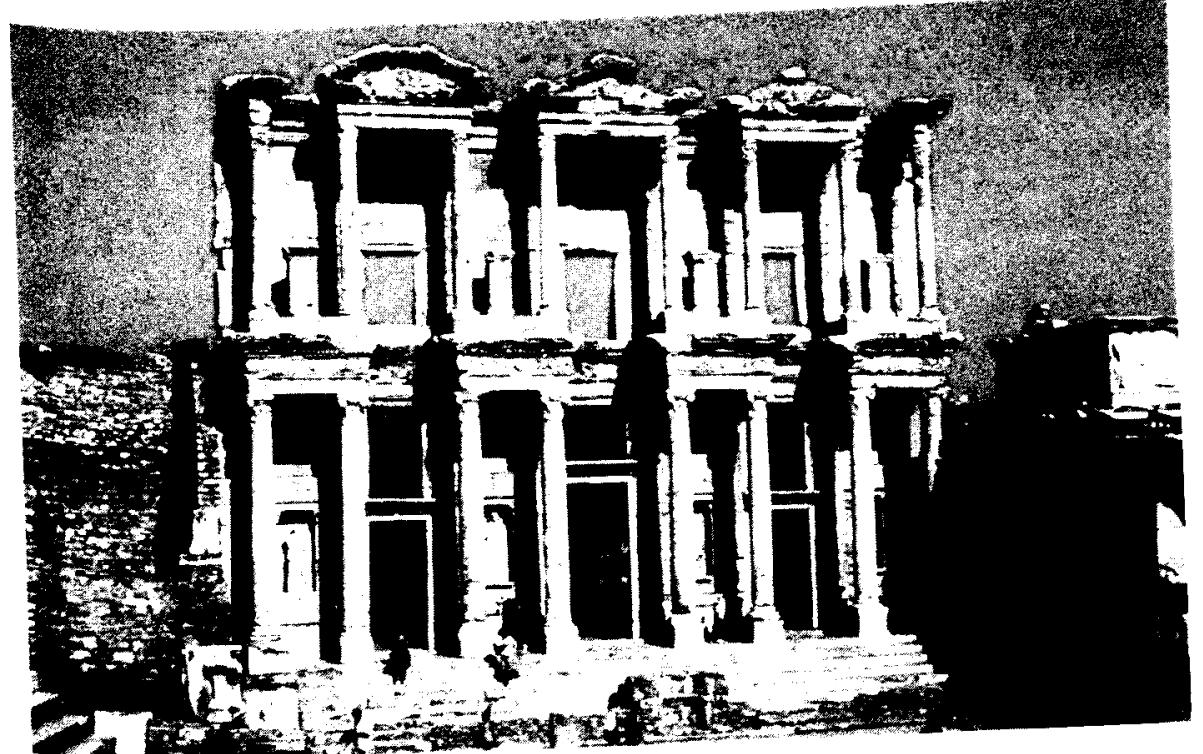

Fig. 3. Biblioteca de Celso en Éfeso; a la derecha, la Puerta de Mazaeus y Mitrídates.

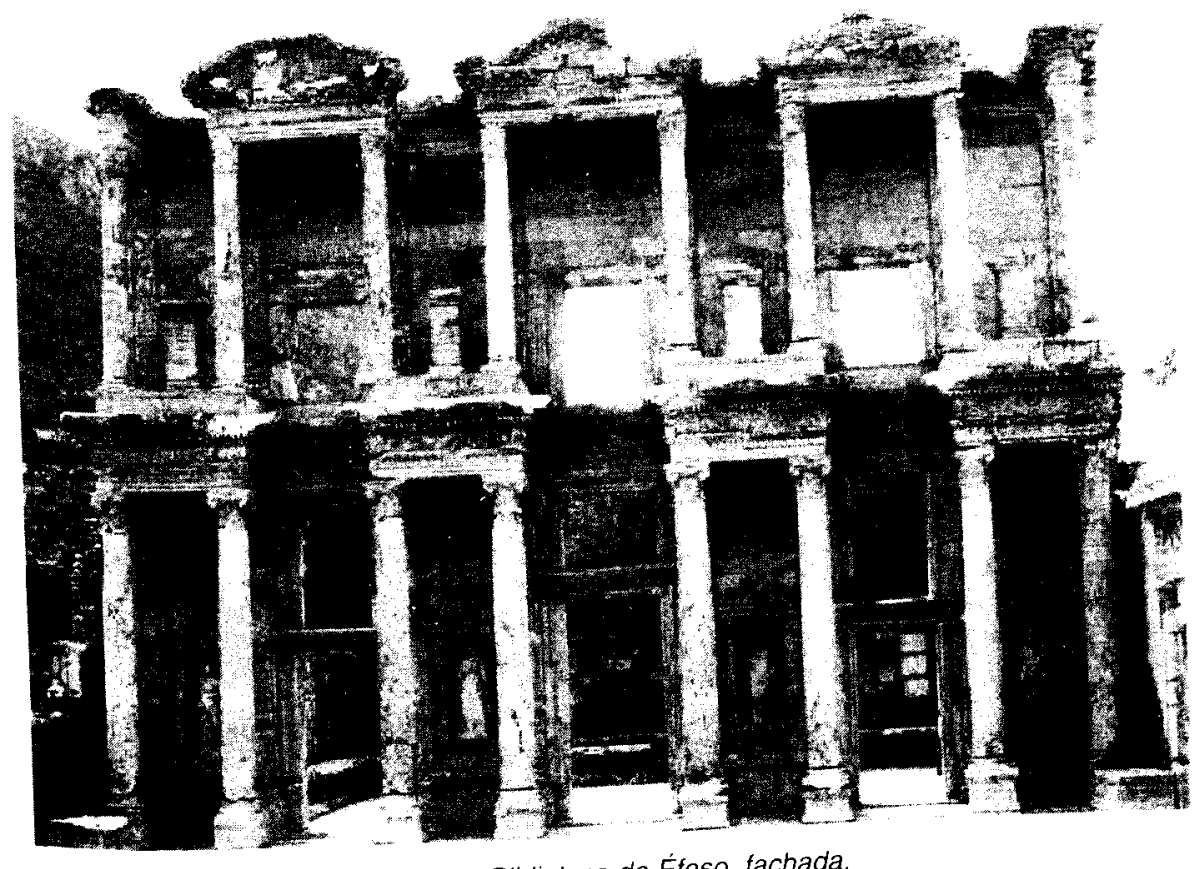

Fig. 4. Biblioteca de Éfeso, fachada. 
de basas áticas, fuste liso y capiteles compuestos, de unos $60 \mathrm{~cm}$ de diámetro inferior, que se elevaban sobre bajos pedestales cuadrados. Los pares de columnas estaban agrupados en cuatro parejas unidas por secciones exentas de entablamento, sobre cada una de las cuales, a su vez, se levantaban dos columnas corintias sin estrías, de gran efecto porque "sorprendentemente, las ocho columnas superiores estaban emparejadas de forma diferente a las de abajo" ${ }^{15}$. Asi, mientras que las columnas de los extremos eran independientes, unidas cada una al muro por un solitario bloque de entablamento saliente, las seis columnas centrales estaban agrupadas en tres parejas por secciones de entablamento. La sección central soportaba un frontón triangular, mientras que las laterales eran circulares, siendo este un recurso ámpliamente utilizado por la arquitectura helenística.

Detrás de las columnas inferiores, la fachada era atravesada por tres puertas, una grande y dos pequeñas, sobre las cuales habia ventanas con celosías de marmol. También en la parte superior habia tres ventanas rectangulares, que seguramente proporcionarían mayor claridad al interior del edificio. Bellas pilastras, magnificamente labradas, enmarcaban cada una de las entradas. Detrás de cada par de columnas, en el muro, se encontraban cuatro hornacinas que contenian sendas estatuas de figuras femeninas, alegorias que simbolizaban las virtudes de Celso: Sophia, Arete, Ennoia y Episteme (la sabiduria, la virtud, la inteligencia y la ciencia). ${ }^{16}$

La escultural fachada fue diseñada para engañar a la vista, haciéndole parecer mayor de lo que es, ya que la base de la fachada fue levantada intencionadamente convexa, añadiendo peso a los elementos centrales. Las columnas centrales eran más largas que las de los extremos, y a su vez, las inferiores mayores que las superiores, consiguiendo de este modo una mayor sensación de monumentalidad. Se añadian de este modo a los elementos tradicionales helenísticos, propios del Asia Menor y modificados por la evolución interna y por ciertos influjos romanos, un refinamiento en el vocabulario artístico, que Ward-Perkins define como de genuína creatividad $^{17}$, siendo el producto de la superposición minuciosamente estudiada

superpuestas en todo tipo de fachadas, una profusa decoración, en formas y colores, con elementos característicos como frontones partidos, entablamentos interrumpidos y comlumnas retorcidas, abundando las formas desarticuladas y salientes. Ver J.J. MARTIN GonzALEZ, Historia del Arte, 2 vol., Ed. Gredos, Madrid 1982.

15. Tal y como destaca Robertson, creando un efecto de gran originalidad. Ver D.S. RoBERTSON, Arquitectura griega y romana, Ed. Cátedra, Madrid 1994.

16 Las estatuas que se pueden contemplar actualmente en la biblioteca son copias de las originales, que se encuentran expuestas en el Museo de Éfeso en Viena.

JoHn WARd-PERKINS, Arquitectura romana. Historia Universal de la Arquitectura, Ed. Aguilar/Asuri, Madrid 1989. 


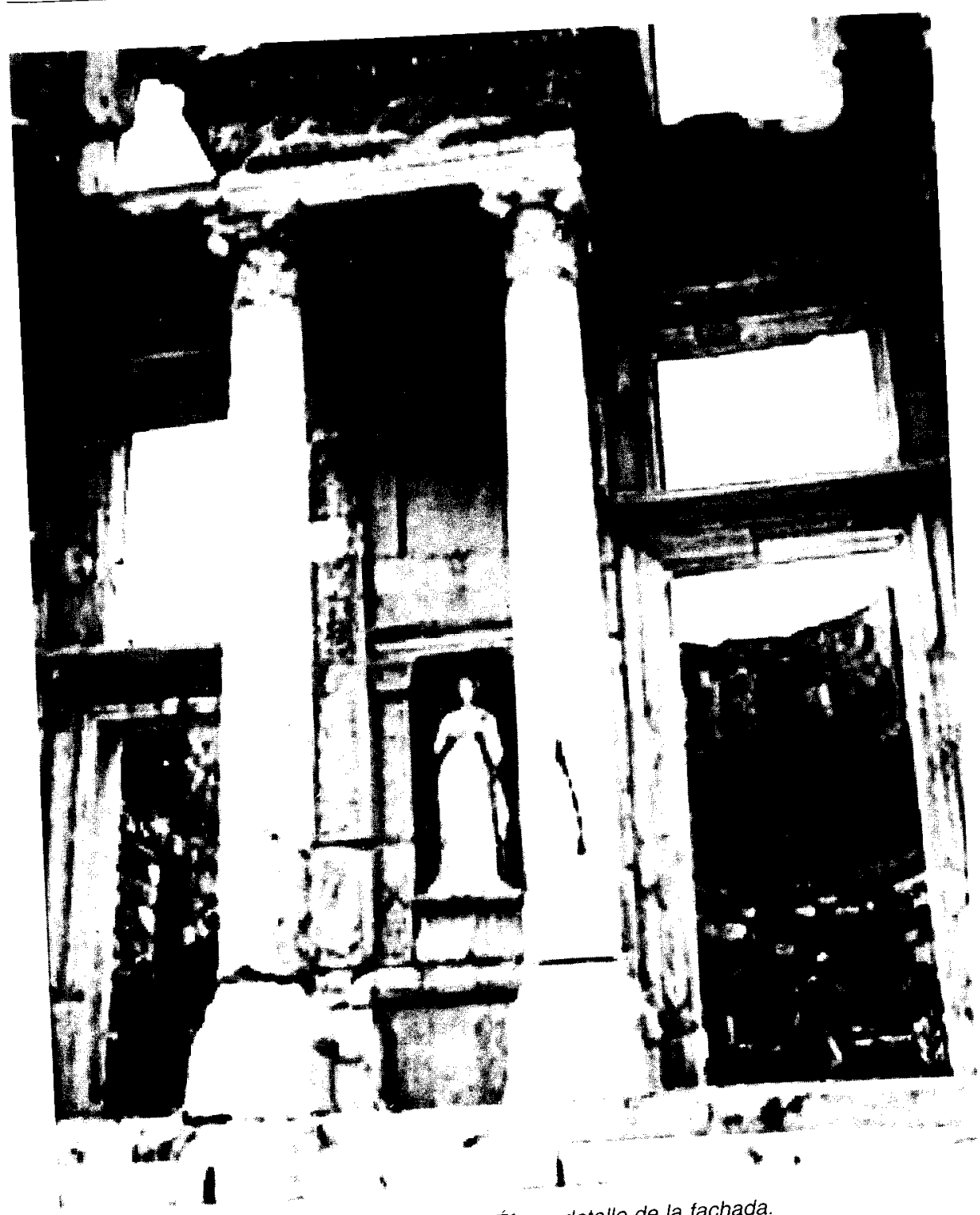

Fig. 5. Biblioteca de Éfeso, detalle de la fachada 
de dos esquemas arquitectónicos contrastantes. Akurgal ${ }^{18}$, por su parte, considera que la aportación más importante a la configuración columnada griega original es la transformación de la enfática horizontalidad helenística por una mayor articulación vertical, como demuestra la biblioteca de Éfeso ${ }^{19}$.

Una vez en el interior, la única sala de la biblioteca tenía $16 \mathrm{~m}$ de altura y estaba cubierta, posiblemente, por un techo de madera, mientras que el suelo estaba completamente cubierto de mármol de variados colores ${ }^{20}$, que proporcionaban al interior una gran vistosidad. Enfrente a la entrada, en el centro del lado opuesto, se encontraba un ábside de más de cuatro

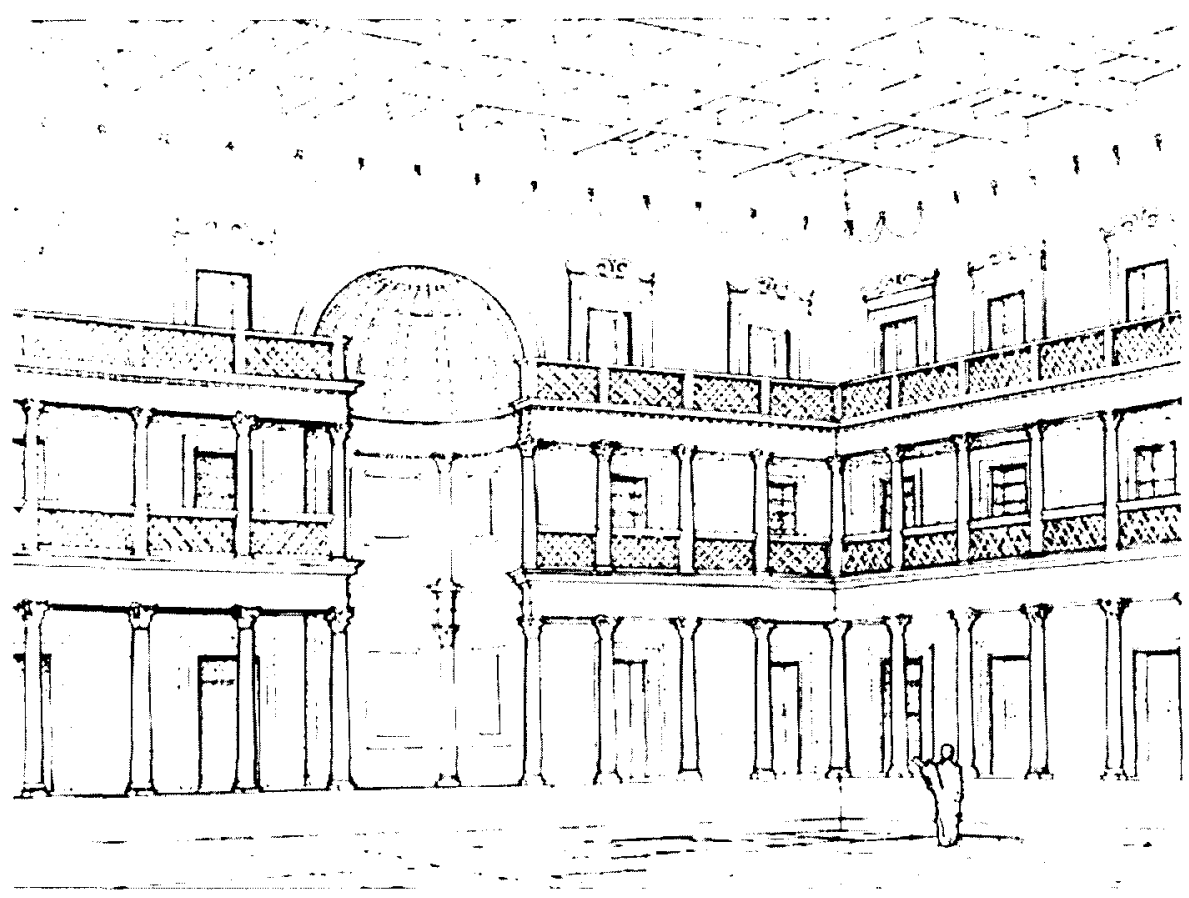

Fig. 6. Reconstrucción del interior de la biblioteca.

Ekrem AkURgal, The art and architecture of Turkey. Oxford University Press, 1980

Sobre la fachada de la biblioteca de Efeso, ver W. WILBERG, Die Fassade der Bibliothek in Ephesus, Österreische Journal History, 11, 1908; F. Hueber-V.M. Sirocka, Die Bibliothek des Celsus. Eine Prachtfassade in Ephesos und das Problem inher Wiederaufrichtung, Ancient World, 6,1975

20 JOSEPH KEIL, Ephesos: ein Führer durch die Ruienstäte und ihre Geschichte. Östereische Archäologisches institut, Viena 1964 
metros de vano. El edificio estaba constituido por muros dobles, para proteger de extremos de temperatura y humedad, garantizando la circulación de aire; únicamente el muro de la fachada y el muro del ábside, más grueso, no tenian esta doble estructura. Entre ambos muros corrían pasadizos semiocultos de más o menos un metro de anchura, a los que se accedía por unas pequeñas y estrechas puertas situadas en ambos lados del edificio. Dobles muros parecidos se han encontrado en la biblioteca de Pérgamo, lo cual parece confirmar que los romanos tomaron los planos de sus bibliotecas de las griegas tardías.

Siguiendo la descripción que hace Robertson ${ }^{21}$, los anaqueles para los libros irían colocados en los 10 nichos situados en los muros interiores exceptuando el de la fachada. Los nichos tienen aproximadamente dos metros de altura y un metro de anchura. Sobre un podio que recorría el perímetro interior de los muros se levantaba una hilera de columnas que probablemente soportaran dos galerias balaustradas superpuestas, a través de las cuales se accedería a los nichos para libros situados en la parte superior. Estas galerías superiores serían accesibles mediante escaleras situadas en los pasadizos antes descritos. No obstante, esta reconstrucción de la parte superior es hipotética, ya que no nos han llegado datos al respecto.La capacidad de la biblioteca era de unos 12.000 volúmenes, lo que la convierte en una de las más grandes de la época.

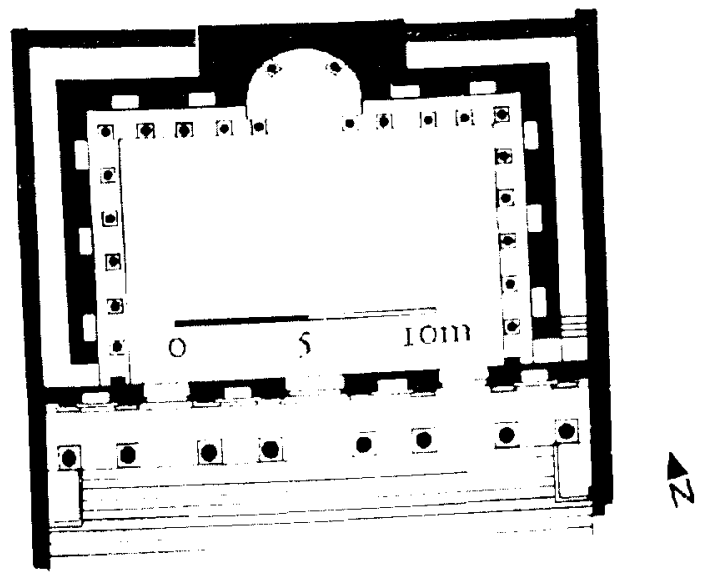

Fig. 7. Plano de la biblioteca. 
El ábside, por otra parte, se encontraba flanqueado por dos columnas adosadas al muro. Lo más probable es que contuviera una estatua de Celso, tal y como consideraba Ward-Perkins ${ }^{22}$, o como ha señalado recientemente Vedat Idil en el Congreso Internacional de Viena ${ }^{23}$.

El pasillo intramuros occidental, además de permitir el acceso a los nichos superiores del lado norte, conducia a unos angostos escalones que bajaban a una cámara abovedada de pequeñas dimensiones, situada justo bajo el ábside, en la que se encontraba un bello sarcófago de mármol blanco, sin duda el de Tiberio Julio Celso Polemeano. Esta cámara fue descubierta por el equipo austriaco en 1904, y como es lógico, el hallazgo supuso una descomunal sorpresa. El sarcófago, todavía intacto, escapó milagrosamente a la destrucción del edificio, en el siglo Iv ó $\vee$ d.C.

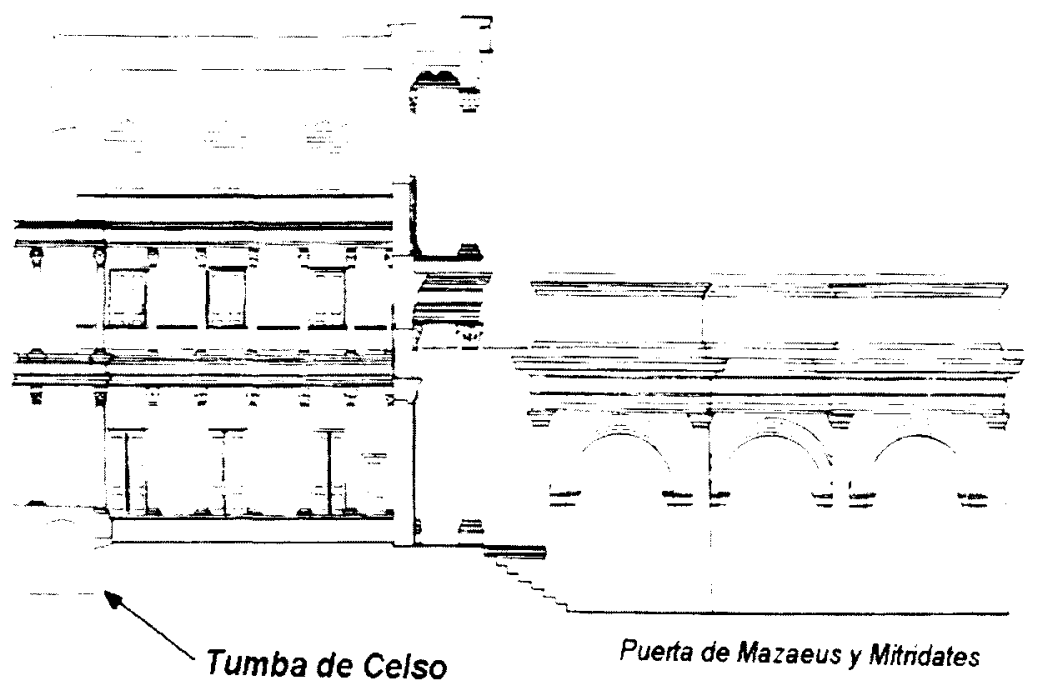

Fig. 8. Vista lateral de la biblioteca con la puerta de Mazaeus y Mitridates.

John WARd-Perkins, Roman Imperial Architecture, Penguin Books, Londres 1981

Vedat Idil, Die Römischen bibliotheken in Kleinasien: Die Celsusbibliotehek in Ephesos und die Bibliothek in Nysa. En FrIESINGer. H.; KrinzInger, F.: 100 Jahre Österreichische Forschungen in Ephesos: Akten des Symposions Wien 1995. Viena, Österreichischen Akademie der Wissenschaften, 1999. 
La biblioteca, de esta manera, servía de heroon, lo que significa que a Celso le fue otorgado el inusual honor de ser enterrado dentro de los límites de la ciudad. Este aspecto es importante para conocer la notoriedad de este personaje, natural seguramente de Sardes, representante de la nueva clase provincial enriquecida que fue ascendida a las más altas instancias del gobierno provincial romano. Una estatua de Celso, hallada en el curso de las excavaciones, se encuentra actualmente expuesta en el Museo Arqueológico de Estambul.

Por sendas inscripciones, en griego y en latín ${ }^{24}$, situadas en las bases de las estatuas laterales de la entrada, conocemos su impresionante cursus honorum.

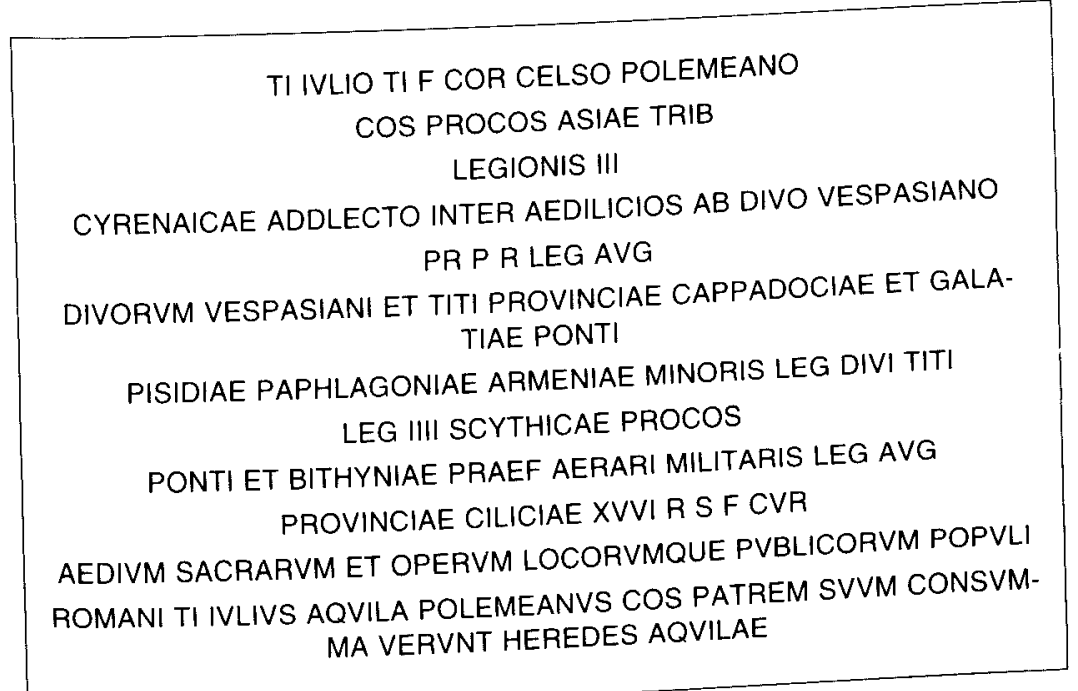

Fig. 9. Inscripción latina en honor al Celso en la que se cita su Cursus Honorum.

D. Magie ${ }^{25}$ sugiere que durante los años 78 y 79 d.C. Celso habría ocupado el cargo de Legati Augusti Propraetore en Bithinia-Pontus; Cilicia Legati Augusti Propraetore cerca del año 90 d.C.; consul de Asia en el

24 Ekkerhard Weber, Zu den lateinischen inschriften von Ephesos. en FRIESINGER, H.; KRINZINGER, F.: 100 Jahre Österreichische Forschungen in Ephesos: Akten des Symposions Wien Akademie der Wissenschaften, 1999, pág 139 a 146. 1950. 
año 92 d.C.; y finalmente Proconsul Propraetore, en el 106-107 d.C. Del resto de los cargos y privilegios que aparecen en las inscripciones no tenemos por el momento datos que permitan obtener una datación precisa. Sin embargo, su larga permanencia en las más altas instancias de la jerarquía provincial romana durante los reinados de Vespasiano, Tito, Domiciano, Nerva y Trajano nos permiten suponer que era un hombre de gran capacidad, máxime teniendo en cuenta que llegó a ocupar el cargo de gobernador provincial; probablemente, esa capacidad reposaba en una ámplia cultura, como podría demostrar el hecho de que el edificio elegido para honrarle fuera una biblioteca. Si parece claro, a la vista de los estudios de V.M.Strocka ${ }^{26}$, que Celso murío probablemente en el año 114 d.C., por lo que la construcción de la biblioteca comenzaría a finales del reinado de Trajano y durante los primeros años de Adriano.

Es interesante, en ese sentido, la apreciación de que en la mayoría de las inaugurationes de la época tanto Trajano como Adriano sean mencionados, teniendo en cuenta que sus reinados permitieron disfrutar de una gran prosperidad en Asia, y sin embargo, no aparezcan en las inscripciones de Éfeso. Las campañas de Trajano y de Adriano contra los partos y otros pueblos orientales alejaron el peligro de incursiones y ataques, al desplazar hacia el Este el limes oriental del Imperio ${ }^{27}$. Las inscripciones honoríficas de la época contenían, en este sentido, un elocuente Gloria Imperii Traiani et Adriani. Tanto el auge económico como el bienestar se ven reflejados en las donaciones, como demuestra la espléndida donación de Gaius Vibius Salutaris, un insigne habitante de Éfeso, miembro del consejo de la ciudad y del ordo ecuestre romano, que donó a la ciudad, en el año 104 d.C., treinta y una figurillas de oro y plata, incluyendo las de Artemisa, el emperador Trajano y su esposa y diversas personificaciones ${ }^{28}$. Por este motivo, como destaca Schowalter, la omisión de estos emperadores en las inscripciones de la biblioteca "resulta particularmente extraña, dado el enorme papel que tuvo Celsus en los asuntos militares y diplomáticos romanos» 29 .

Los datos que tenemos sobre la historia posterior de la biblioteca son muy escasos. Sabemos, como se ha dicho anteriormente, que Julio Aquila

\footnotetext{
26 V.M. StrockA, Zur Datierung der Celsusbibiothek, en Proceedings of the $X^{\text {th }}$ International Cogress of Classical Archaelogy, Ankara 1973 (1978). Págs. 893 y stes.

27 Fergus Millar, The Roman Near East, 31 B.C.-A.D. 337.: Harvard University Press, 1993.

28 Cit. David MAGIE.

29 Daniel SCHOWALTER, Honoring the emperor: the Ephesiasn respond to Trajan. En Friesinger, H.; Krinzinger, F.: 100 Jahre Österreichische Forschungen in Ephesos: Akten des Symposions Wien 1995. Viena, Österreichischen Akademie der Wissenschaften, 1999.
} 


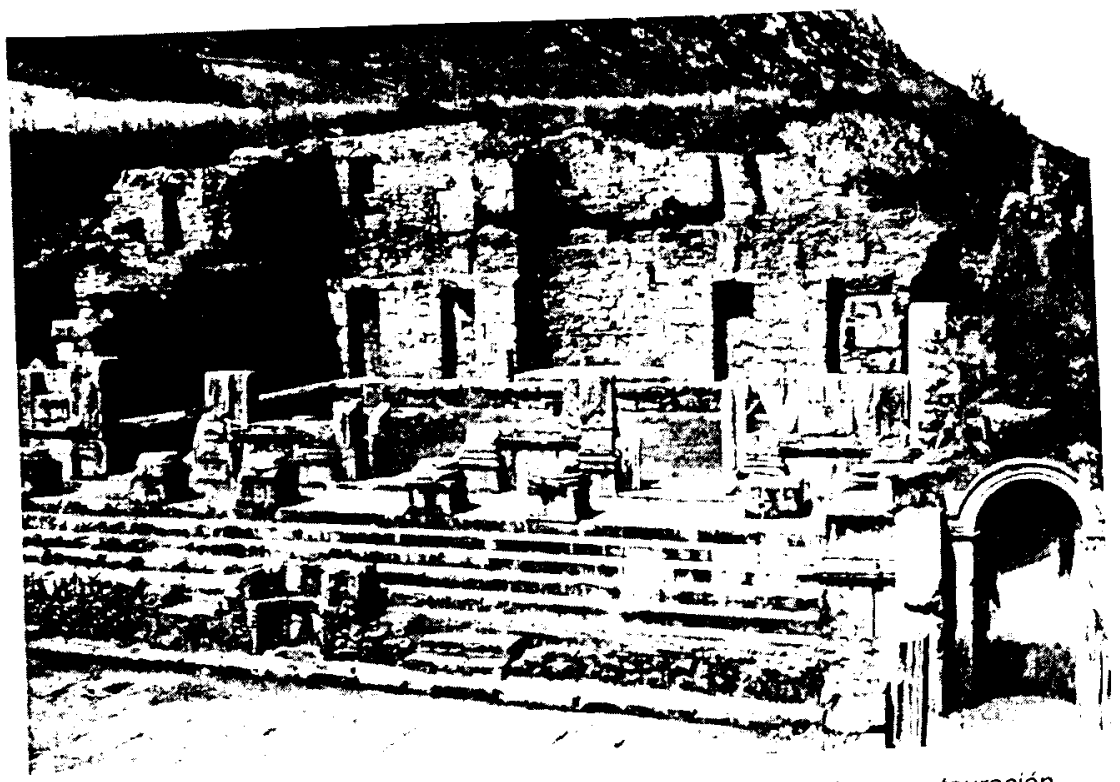

Fig. 9. Biblioteca de Éfeso. Fotografía del edificio antes de su restauración.

Polemeano, hijo de Celso, financió la construcción y la compra de libros para la biblioteca, que fue finalizada por su nieto. De los libros que adquirió la institución y poblaron sus estantes en realidad nada ha llegado hasta nosotros; sin embargo, es posible que constara de dos secciones, al igual que las bibliotecas públicas romanas, una para libros escritos en latín y otra para libros escritos en griego, que presumiblemente serían mayoría, dada la honda herencia helenística del Asia Menor. Podemos conjeturar que abundaran las obras literarias, históricas, filosóficas, y atendiendo al carácter práctico de la civilización romana, también las referentes a la agricultura, a las artes de la guerra, a la medicina o a la ingeniería ${ }^{30}$. Es seguro que las lecturas, siguiendo el gusto griego y romano, se harian en el exterior del edificio, sentados en los escalones de entrada o paseando por la plaza, y probablemente la lectura se haría en voz alta. Evidentemente en esta época las bibliotecas no contaban con mesas de lectura, ya que éstas se incorporaron a las bibliotecas ya en la época bizantina, cuando comenzaron a sustituirse los rollos de pergamino o papiro, cuya lectura requería de la utilización de ambas manos, por los codices, más voluminosos y pesados.

30 Hipólito Escolar, Historia de las bibliotecas. Fundación Germán Sánchez Ruipérez, Madrid, 1990. 
Si parece seguro que la biblioteca se mantuvo en funcionamiento hasta el año 262 d.C., año en el que se produjo la incursión de los godos en Éfeso. Aunque no se puede afirmar con absoluta certeza, parece ser que la biblioteca fue incendiada en dicho ataque, aunque el muro frontal no fue destruido totalmente. El hecho de que aún fuera utilizada parece probado porque fue restaurada después del desastre, y una hermosa fuente fue construída delante de la fachada. En las cercanias se encontraron fragmentos de un friso monumental de losas talladas en relieve, de carácter narrativo, que tradicionalmente se ha interpretado como conmemorativo de las victorias de Lucio Vero y Marco Aurelio contra los partos, aunque Vermeule lo ha fechado anteriormente, hacia el 138 d.C., fecha en la que murió Adriano, sin que hasta el momento se conozca cual fue la ubicación originaria del friso ${ }^{31}$. Los fragmentos del friso se encuentran expuestos en el Museo de Éfeso en Viena.

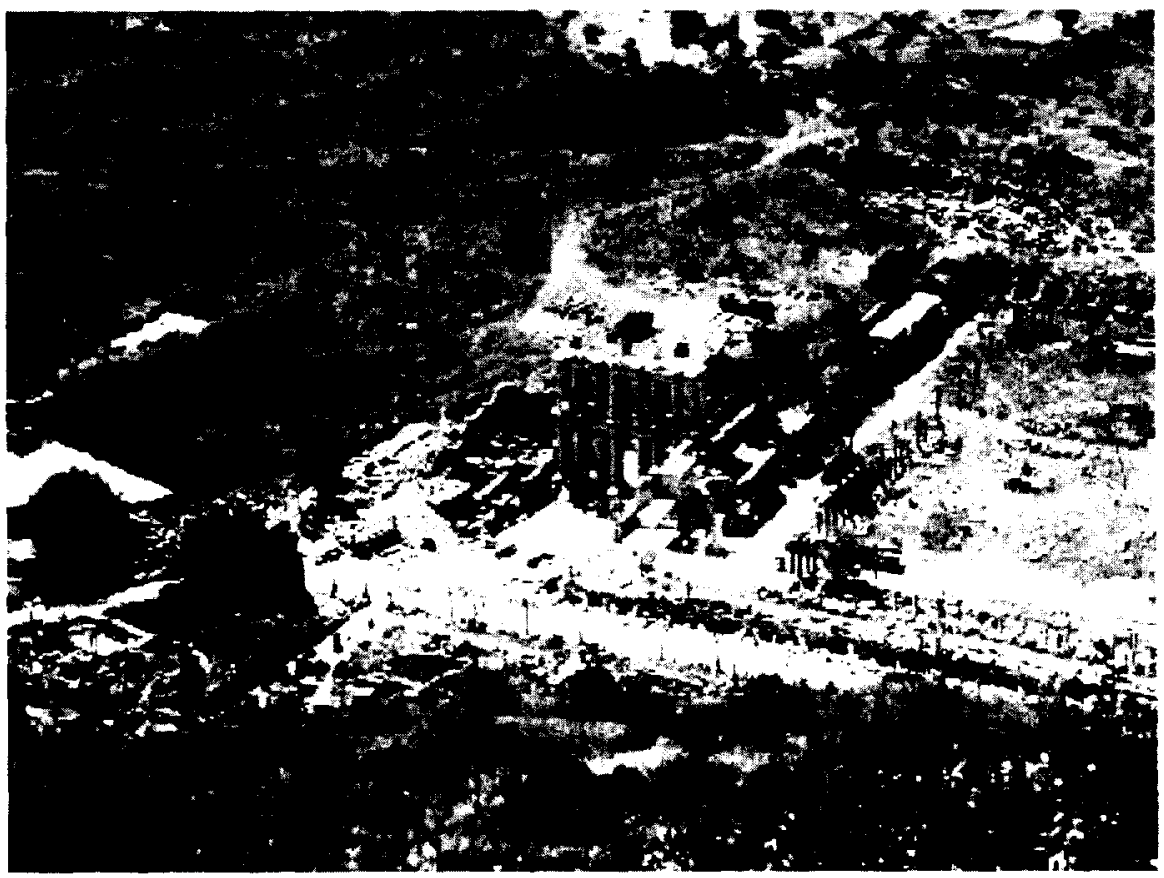

Fig. 10. Biblioteca de Éfeso; a la derecha, el Ágora.

31. Cornelius C. Vermeule, Roman Imperial Art in Greece and Asia Minor. Harvard University Press, 1968 
Las restauraciones fueron completadas alrededor del siglo IV. No obstante, la destrucción del edificio debió producirse entre este siglo y el siguiente, seguramente incendiado. Como ocurrió con el templo de Artemisa, fue despojado de lo que tenía de valor, además de que parte de los materiales del edificio fueron reutilizados en la construcción de otros nuevos.

Es necesario mencionar la monumental labor realizada por el Austrian Archaeological Institute y sus investigadores en la reconstrucción de la biblioteca de Éfeso, desde que en 1903 comenzaron las excavaciones arqueológicas en el edificio.

Cuando los investigadores austriacos iniciaron los estudios en la biblioteca de Celso, su estado podría calificarse de ruinoso, pues apenas tenía los cimientos. Sin embargo, a mediados de siglo, y gracias a las aportaciones de varios investigadores y al excelente trabajo de $W$. Wilberg, creador de una larga colección de dibujos sobre la reconstrucción de la biblioteca, se empezó a conocer mucho mejor el aspecto que ésta habría tenido en el siglo II.

Basándose en esos estudios, en el otoño de 1970 se iniciaron los trabajos de reconstrucción de la fachada, un ambicioso proyecto que no obstante el Austrian Archaeological Institute pudo llevar a cabo, a través de un equipo de investigadores austriacos y alemanes, dirigidos por el arqueólogo V.M.Strocka y el arquitecto-restaurador F. Weber. Finalmente, los trabajos de reconstrucción se dieron por concluidos en el año 1978, después de una ingente labor. Tienen nuestro agradecimiento más sincero. 